\title{
Comparative Analysis between Total Disc Replacement and Posterior Foraminotomy for Posterolateral Soft Disc Herniation with Unilateral Radiculopathy : Clinical and Biomechanical Results of a Minimum 5 Years Follow-up
}

\author{
Kyoung-Tae Kim, M.D., ${ }^{1}$ Dae-Chul Cho, M.D., ${ }^{1}$ Joo-Kyung Sung, M.D., ${ }^{1}$ Young-Baeg Kim, M.D., ${ }^{2}$ Du Hwan Kim, M.D. ${ }^{3}$ \\ Department of Neurosurgery, Kyungpook National University Hospital, Daegu, Korea \\ Department of Neurosurgery, ${ }^{2}$ Chung-Ang University Hospital, Seoul, Korea \\ Department of Rehabilitation Medicine, Keimyung University Hospital, Daegu, Korea
}

Objective : To compare the clinical outcomes and biomechanical effects of total disc replacement (TDR) and posterior cervical foraminotomy (PCF) and to propose relative inclusion criteria.

Methods : Thirty-five patients who underwent surgery between 2006 and 2008 were included. All patients had single-level disease and only radiculopathy. The overall sagittal balance and angle and height of a functional segmental unit (FSU; upper and lower vertebral body of the operative lesion) were assessed by preoperative and follow-up radiographs. C2-7 range of motion (ROM), FSU, and the adjacent segment were also checked.

Results : The clinical outcome of TDR (group A) was tended to be superior to that of PCF (group B) without statistical significance. In the group $A$, preoperative and postoperative upper adjacent segment level motion values were $8.6 \pm 2.3$ and $8.4 \pm 2.0$, and lower level motion values were $8.4 \pm 2.2$ and $8.3 \pm 1$.9. Preoperative and postoperative FSU heights were $37.0 \pm 2.1$ and $37.1 \pm 1.8$. In the group $B$, upper level adjacent segment motion values were $8.1 \pm 2.6$ and $8.2 \pm 2.8$, and lower level motion values were $6.5 \pm 3.3$ and $6.3 \pm 3.1$. FSU heights were $37.1 \pm 2.0$ and $36.2 \pm 1.8$. The postoperative FSU motion and height changes were significant $(p<0.05)$. The patient's satisfaction rates for surgery were $88.2 \%$ in group $A$ and $88.8 \%$ in group $B$.

Conclusion : TDR and PCF have favorable outcomes in patients with unilateral soft disc herniation. However, patients have different biomechanical backgrounds, so the patient's biomechanical characteristics and economic status should be understood and treated using the optimal procedure.

Key Words : Total disc replacement · Foraminotomy · Cervical disc · Radiculopathy.

- Received: June 1, 2015 •Revised: October 13, 2015 •Accepted: October 14, 2015

- Address for reprints : Kyoung-Tae Kim, M.D., Ph.D.

Department of Neurosurgery, Kyungpook National University Hospital, 130 Dongdeok-ro, Jung-gu, Daegu 41944, Korea

Tel : +82-53-200-5657, Fax : +82-53-423-0504, E-mail: nskimkt7@gmail.com

This is an Open Access article distributed under the terms of the Creative Commons Attribution Non-Commercial License (http://creativecommons.org/licenses/by-nc/4.0) which permits unrestricted non-commercial use, distribution, and reproduction in any medium, provided the original work is properly cited. 


\section{INTRODUCTION}

Various surgical approaches have been described to treat cervical disc disorders causing radiculopathy ${ }^{1,3,4,7,19,21,27)}$. Among these approaches, anterior cervical discectomy with bone fusion (ACDF) was developed in the 1950s to achieve direct decompression of the herniated disc fragment ${ }^{6}$, and it has been widely adopted for treating of cervical radiculopathy in the past 50 years. However, fusion techniques can increase adjacent segment disease or degeneration after surgery. To decrease these problems and to preserve segmental motion, total disc replacement (TDR) and posterior cervical foraminotomy (PCF) have been developed as alternative surgical techniques ${ }^{8-10,12,24,28-30)}$. Posterolateral soft disc herniation with unilateral radiculopathy is a good indication for both procedures, both of which provide good clinical outcomes. However, there are currently no substantiated comparative biomechanical and clinical results with long-term follow-up. This study was designed to compare the clinical outcomes and biomechanical changes after TDR and PCF with at least 5 years of follow-up.

\section{MATERIAL AND METHODS}

\section{Patients}

This retrospective study was designed to evaluate surgical procedures for patients presenting with unilateral cervical radiculopathy caused by a posterolateral soft disc herniation. We selected patients who underwent TDR or PCF between January 2006 and December 2008. All patients had singlelevel disease and only unilateral radiculopathy without myelopathy. Patients with traumatic injury, neoplasm, a previous cervical operation, or myelopathy were excluded.

TDR (group A) and PCF (group B) were performed in 18 and 20 patients, respectively. Complete data with a long-term follow-up evaluation were available for 35 patients (group A: 17, and group B: 18); three patients could not be contacted. Preoperative and perioperative data were obtained by reviewing patients' charts and radiologic examinations, and surgi- cal outcomes were determined based on clinical outpatient follow-up with radiologic examinations. The follow-up period ranged was $60-95$ months (mean, 83.2 \pm 15.9 months). All patients underwent preoperative computed tomography and magnetic resonance imaging. Preoperative overall sagittal balance and functional segmental unit (FSU; upper and lower vertebral body of operative lesion) angle and height were assessed by preoperative and follow-up static neutral lateral radiographs. C2-7 range of motion (ROM), FSU, and the adjacent segment were also checked by dynamic radiography.

\section{Surgical techniques}

A conventional anterior cervical approach was used in group A via a transverse incision in all cases. A complete discectomy with sufficient foraminal and central decompression was routinely performed. The posterior longitudinal ligament was routinely removed. A rasp was used to complete the endplate preparation. A rail cutter guide was used to prepare the implant fixation channels. A fixation channel in the endplate was drilled, and a rail punch was impacted into the disc space. The Prestige LP (Medtronics Sofamor Danek, Memphis, TN, USA) disc rails were aligned with the channels on the endplates and inserted. Anterior-posterior and lateral fluoroscopy was performed to verify proper placement. All patients were encouraged to ambulate without neck braces immediately after surgery.

PCF was performed by using a tubular retractor (METRx system; Medtronic Sofamor Danek, Memphis, TN, USA) and a microscope in group $\mathrm{B}^{12,18)}$. A skin incision was made approximately $5 \mathrm{~mm}$ ipsilateral to the midline at the target level. The cervical fascia was incised equal to the length of the incision using a monopolar cautery, and tubular muscle dilators were serially placed. After dilation was complete, a final working channel (16- $\mathrm{mm}$ or $18-\mathrm{mm}$ tubular retractor) was placed over the dilators and fixed over the laminofacet junction with a table-mounted flexible retractor arm, and the dilators were removed. Partial hemilaminectomy and foraminotomy with partial facetectomy at the target level was performed under a microscope. The proximal root was adequately visualized for removal of the compressing disc mate- 
rial. The patients were placed in a soft collar for 2-3 weeks postoperatively.

\section{Assessment of clinical and radiological outcomes}

Preoperative and postoperative neurological status, visual analog scale (VAS) score of the neck and arm, and the neck disability index (NDI) were evaluated routinely. Surgery-related complications, such as hoarseness, dysphagia, and cerebrospinal fluid leakage, were also investigated. We regarded the surgery as a success if postoperative NDI improvement was more than 15 points at the final follow-up (minimum 5 years) without repeat surgery.

The overall cervical sagittal balance and FSU angle and height were assessed on preoperative and postoperative static neutral lateral radiographs (Fig. 1). C2-7 ROM, FSU, and the adjacent segment were assessed by dynamic cervical spine radiographs (Fig. 2). Lordosis was shown as a negative value, and kyphosis was shown as a positive value. To compare changes in disc height, we also examined FSU height compensated for by radiological magnification errors. The reason we measured FSU height instead of actual disc space height was that endplate milling in TDR made it difficult to compare disc height changes. The incidence of heterotopic ossification (HO) in group A was assessed according to the McAfee classification $^{22)}$. We measured the angles with quantitative measurement analysis software on a PACS workstation (Centricity 2.0; General Electric Medical Systems, Milwaukee, WI, USA).

\section{Assessment of patient satisfaction and cognition for surgery}

We asked the patients 1 year after surgery: "Are you satisfied with the results of surgery?" and "Would you choose the same procedure again?" Additionally, we asked the patients "What do you think was the best benefit of your procedure?"
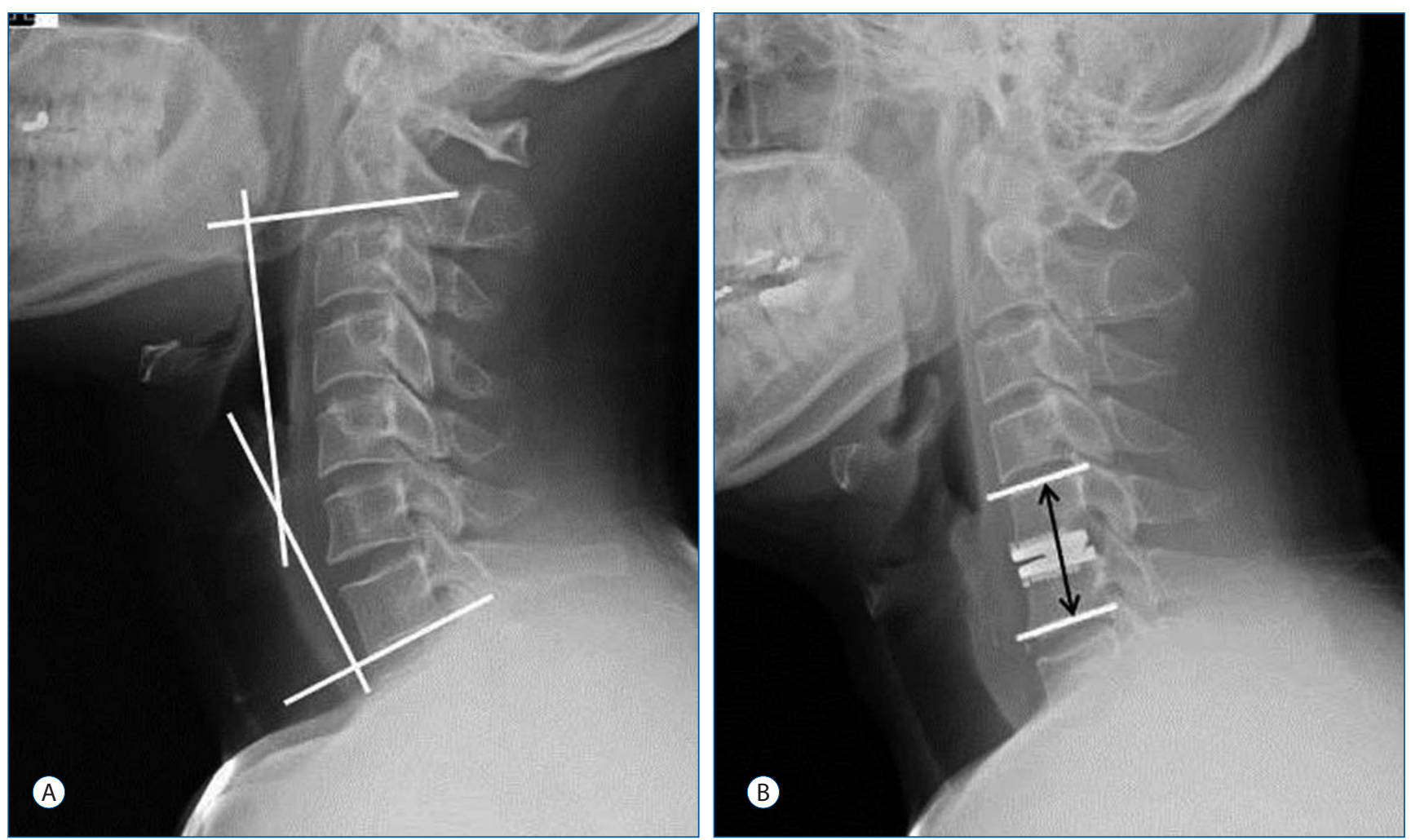

Fig. 1. A : Sagittal balance was measured as the angle between the lower margin of C2 and C7 on a static neutral lateral radiograph. B : Functional segmental unit (FSU; upper and lower endplate of the operative lesion) height was measured as the length from the upper endplate of the superior segment to the lower endplate of the inferior segment at the operated level. 


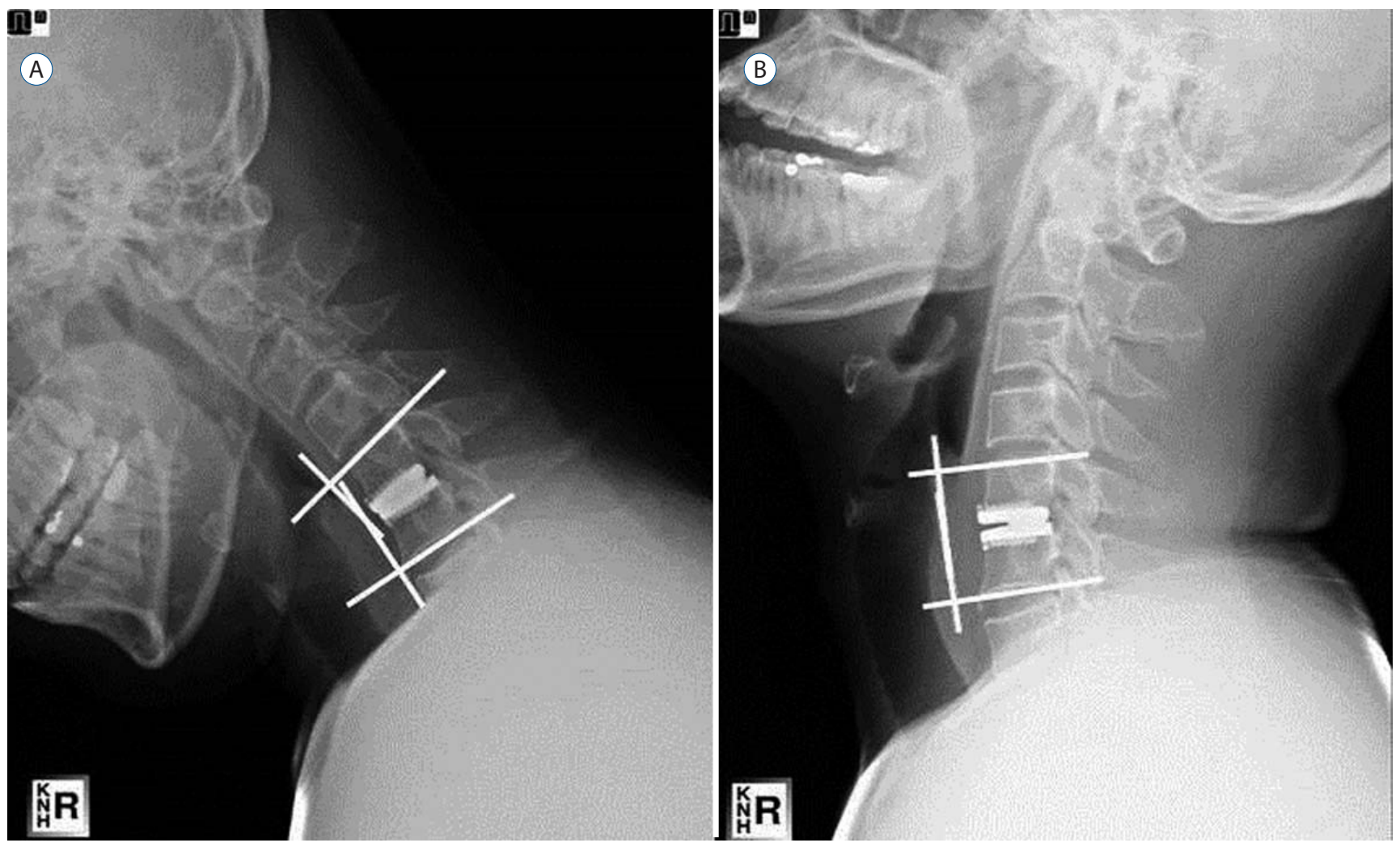

Fig. 2. Range of motion was measured as the difference of the angle on a simple dynamic radiograph.

Table 1. Patient characteristics

\begin{tabular}{|c|c|c|c|}
\hline Variable & Group A (17 patients) & Group B (18 patients) & $p$-value \\
\hline Mean age (yr, range) & $42.1 \pm 5.5(29-51)$ & $42.8 \pm 5.9(33-49)$ & 0.680 \\
\hline Gender (male : female) & $12: 5$ & $11: 7$ & 0.725 \\
\hline Affected lesion & & & 0.347 \\
\hline C4-5 (\%) & $5(29.4)$ & $5(27.8)$ & \\
\hline C5-6 (\%) & $7(41.2)$ & $5(27.8)$ & \\
\hline C6-7 (\%) & $5(29.4)$ & $5(27.8)$ & \\
\hline C7-T1 (\%) & 0 & $3(16.6)$ & \\
\hline Duration of symptom (mon, range) & $5.1 \pm 3.4(3-16)$ & $4.4 \pm 3.0(1-18)$ & 0.483 \\
\hline Surgical time (min, range) & $90.3 \pm 17.6(63-119)$ & $77.4 \pm 18.3(52-114)$ & 0.041 \\
\hline Length of hospital stay (day, range) & $6.9 \pm 2.2(5-18)$ & $4.1 \pm 1.8(3-15)$ & 0.032 \\
\hline Follow-up period (mon, range) & $82.5 \pm 15.4(61-91)$ & $84.1 \pm 16.1(60-95)$ & 0.783 \\
\hline
\end{tabular}

Group A : total disc replacement. Group B : posterior cervical foraminotomy

\section{Statistical analysis}

Differences in the clinical and radiological results of each group were evaluated by the Wilcoxon signed-rank test with SPSS software for Windows ver. Version 18.0 (SPSS Inc., Chicago, IL, USA).

We applied nonparametric statistical tests exclusively, such as the $\chi^{2}$ test, the Fisher's exact test, the $t$-test, and the MannWhitney $U$ test, as appropriate. The mean values of the groups were compared by using $t$-tests after performing $\mathrm{F}$ tests for homogeneity of variances. A $p$-value $<0.05$ was considered significant. Nonparametric correlation analyses were performed using the Spearman-rho rank-ordered correlation 
coefficient and the Kendall-tau coefficient analyses to detect associations between categorical variables.

\section{RESULTS}

\section{Clinical outcomes}

Patient demographics and preoperative neurological status are summarized in Table 1, 2. No differences in these variables were observed between the groups, except length of hospital stay, which may have been associated with early surgical complications (Table 3 ). The difference in early complication was caused by using the anterior approach.

Clinical outcomes are summarized in Table 4. Preopera-

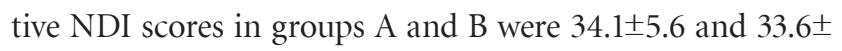
8.4 , and the postoperative NDI scores were 9.5 \pm 3.4 and $9.9 \pm$ 4.7 , respectively. The success rate of group A was $94.1 \%$, which was slightly superior to that of group B (88.9\%), but the difference was not significant. No surgical complications were detected in group B, whereas group A had four cases of complications $(23.5 \%)$, but all were transient. Operating time and hospitalization time were $90.3 \pm 17.6 \mathrm{~min}$ and $6.9 \pm$ $2.2 \mathrm{~d}$ in group $\mathrm{A}$, and $77.4 \pm 18.3 \mathrm{~min}$ and $4.1 \pm 1.8 \mathrm{~d}$ in group $\mathrm{B}$, respectively.

Table 2. Preoperative neurological statuses

\begin{tabular}{lccc}
\hline Symptoms & $\begin{array}{c}\text { No. patients in } \\
\text { group A (\%) }\end{array}$ & $\begin{array}{c}\text { No. patient in } \\
\text { group B (\%) }\end{array}$ & p-value \\
\hline Motor deficits & $9(52.9)$ & $11(61.1)$ & 0.625 \\
Sensory deficits & $13(76.5)$ & $14(77.8)$ & 0.927 \\
Pain only & $2(11.8)$ & $2(11.1)$ & 0.952 \\
Altered reflex & $10(56.8)$ & $12(66.7)$ & 0.631 \\
\hline
\end{tabular}

Group A : total disc replacement. Group B : posterior cervical foraminotomy
Repeat surgery was necessary for a 48-year-old male patient in group B at 4 years after primary surgery. He experienced an ipsilateral recurrent arm pain causing progression of spondylosis (Fig. 3) and underwent anterior discectomy and fusion.

\section{Radiologic data}

The overall biomechanical data are summarized in Table 5. The preoperative C2-7 angle and FSU in group A were -13.4 \pm 11.6 and $-0.2 \pm 3.8$, and the postoperative $\mathrm{C} 2-7$ angle and FSU were $-14.0 \pm 10.4$ and $0.4 \pm 3.8$, respectively. Preoperative C2-7 ROM and FSU were $44.5 \pm 6.3$ and $10.0 \pm 1.6$, and the postoperative values were $44.3 \pm 5.7$ and $8.4 \pm 2.1$, respectively. Preoperative and postoperative upper level adjacent segment motion values were $8.6 \pm 2.3$ and $8.4 \pm 2.0$, and the lower level motion values were $8.4 \pm 2.2$ and $8.3 \pm 1.9$, respectively. Preoperative and postoperative FSU heights were $37.0 \pm 2.1$ and $37.1 \pm 1.8$, respectively. Postoperative FSU ROM decreased significantly final follow-up ( $p=0.007$ ), which was caused by HO (Table 6). We also found a high rate of $\mathrm{HO}$ in group A $(70.6 \% ; 12 / 17)$. In particular, severe $\mathrm{HO}$ (grade III+IV) was directly relevant to segmental motion $(29.4 \% ; 5 / 17)$. However, the occurrence of HO was not related with clinical outcomes (Table 7).

Preoperative C2-7 angle and FSU in group B were $-14.0 \pm$ 10.4 and $0.4 \pm 3.8$, and postoperative $\mathrm{C} 2-7$ angle and FSU were $-12.8 \pm 9.5$ and $0.6 \pm 4.5$, respectively. Preoperative C2-7 ROM and FSU were $44.9 \pm 8.3$ and $10.4 \pm 1.5$, and the postoperative values were $44.0 \pm 8.0$ and $8.2 \pm 1.9$, respectively. Preoperative and postoperative upper level adjacent segment motion values were $8.1 \pm 2.6$ and $8.2 \pm 2.8$, and the lower level motion values were $6.5 \pm 3.3$ and $6.3 \pm 3.1$, respectively. Preoperative and postoperative FSU heights were $37.1 \pm 2.0$ and $36.2 \pm 1.8$, respec-

Table 3. Surgery-related complications

\begin{tabular}{|c|c|c|c|c|c|}
\hline & \multicolumn{2}{|c|}{ No. patients in group A } & \multicolumn{2}{|c|}{ No. patient in group B } & \multirow{2}{*}{$p$-value } \\
\hline & Transient & Permanent & Transient & Permanent & \\
\hline Hoarseness & 2 & 0 & 0 & 0 & \\
\hline Dysphagia & 2 & 0 & 0 & 0 & \\
\hline Cerebrospinal fluid leak & 0 & 0 & 0 & 0 & \\
\hline Total complications (\%) & \multicolumn{2}{|c|}{$4(23.5)$} & \multicolumn{2}{|c|}{$0(0.0)$} & 0.045 \\
\hline
\end{tabular}

Group A : total disc replacement. Group B : posterior cervical foraminotomy 

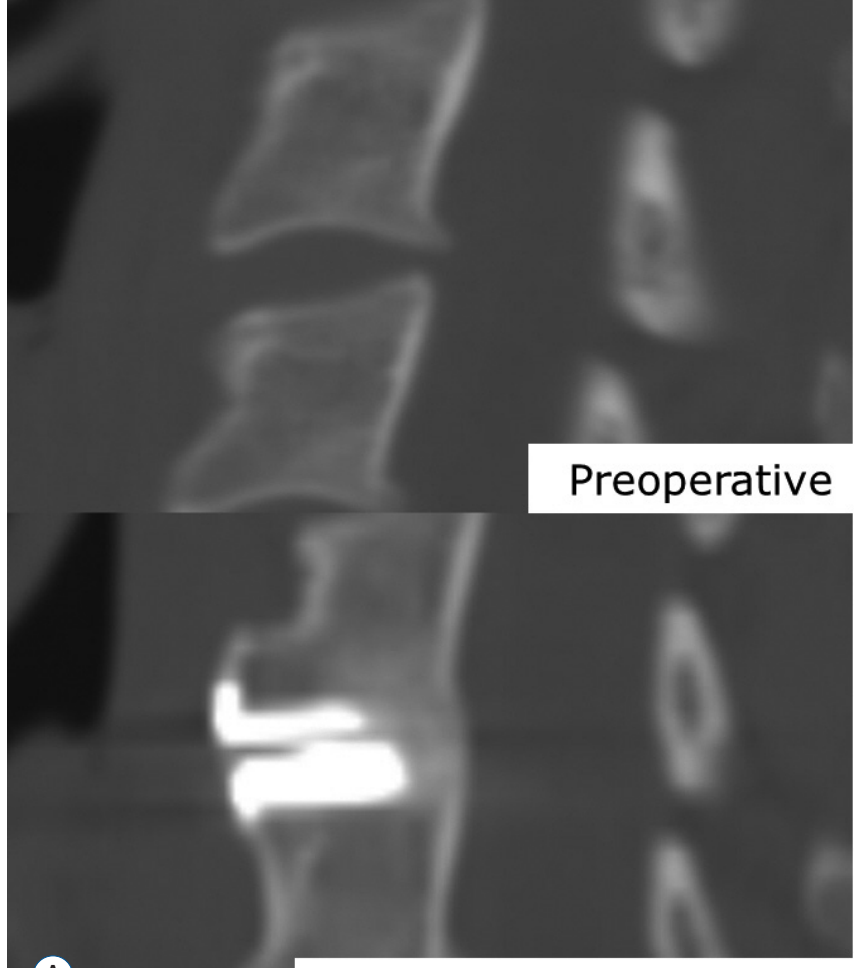

A

At 5 years after surgery

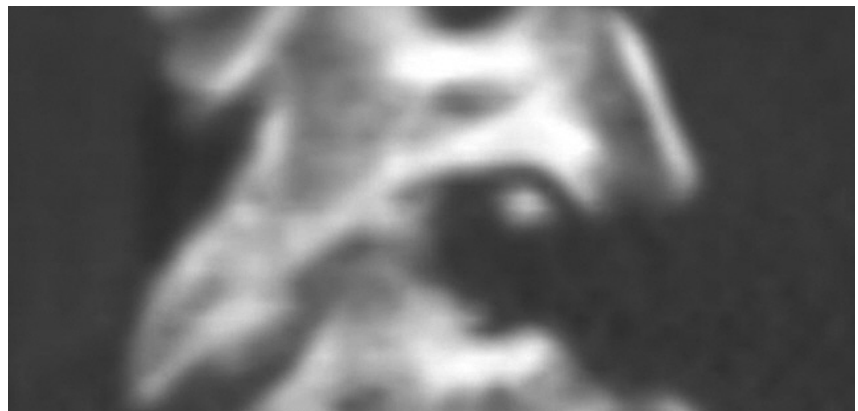

At 5 days after surgery

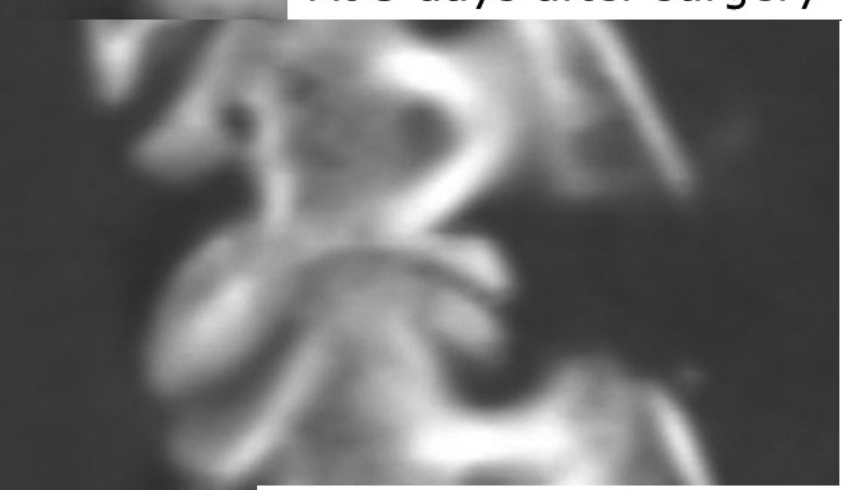

B

At 4 years after surgery

Fig. 3. Case 1 in the total disc replacement (A). At 5 years after surgery, severe heterotophic ossification was shown on a computed tomography scan, but no clinical symptoms were observed. Case 2 in the posterior cervical foraminotomy (B). The patient complained of recurrent arm pain 4 years after the surgery, so we performed anterior cervical fusion as the revision surgery.

Table 4. Long-term outcomes after the operation

\begin{tabular}{lccc}
\hline Variable & Group A & Group B & $\boldsymbol{p}$-value \\
\hline NDI & & & \\
Preoperative & $34.1 \pm 5.6$ & $33.6 \pm 8.4$ & 0.854 \\
Postoperative & $9.5 \pm 3.4$ & $9.9 \pm 4.7$ & 0.767 \\
$\begin{array}{l}\text { VAS of neck } \\
\text { Preoperative }\end{array}$ & $2.9 \pm 1.1$ & $2.9 \pm 1.0$ & 0.986 \\
Postoperative & $1.1 \pm 0.7$ & $1.2 \pm 0.9$ & 0.664 \\
VAS of arm & & & \\
Preoperative & $7.0 \pm 1.2$ & $6.9 \pm 1.1$ & 0.889 \\
Postoperative & $1.3 \pm 0.8$ & $1.6 \pm 0.8$ & 0.278 \\
Success* & $16(94.1)$ & $16(88.9)$ & 0.581 \\
\hline
\end{tabular}

Values are presented as mean \pm standard deviation or number (\%). Group A : total disc replacement. Group B : posterior cervical foraminotomy. *NDI improvement of more than 15 points at the final follow-up with no device failure or major complication. NDI : neck disability index, VAS visual analog scale

tively. Postoperative FSU motion and height changes were significant compared to those taken preoperatively $(p<0.05)$. The decrease in FSU height tended to be associated with clin- ical outcomes ( $p=0.068$; Table 7 ). Cervical foraminal stenosis was aggravated by the decrease in FSU height, and it may have increased the arm VAS and NDI scores. Additionally, we compared the degree of biomechanical changes between group A and B. The postoperative change in $\mathrm{C} 2-7$ sagittal alignment (group A, $0.1 \pm 0.1$; group B, $1.2 \pm 0.4, p=0.043$ ), ROM of FSU (group A, 1.6 \pm 0.5 ; group B, $2.2 \pm 0.6, p=0.039$ ), and FSU height (group A, $0.1 \pm 0.0$; group $\mathrm{B}, 0.9 \pm 0.1, p=0.033$ ) were significantly higher in group $\mathrm{B}$ than those in group $\mathrm{A}$.

\section{Patient satisfaction and cognition for surgery}

We asked the patients 1 year after surgery: "Are you satisfied with the results of surgery?" and "Would you choose the same procedure again?" The satisfaction rates of group A and B were $88.2 \%$ and $88.8 \%$, respectively. The "yes" rates in group A and B for the second question were $82.3 \%$ and $83.3 \%$. Additionally, we asked the patients "What do you think was the best benefit of your procedure?", "Motion pres- 
Table 5. Biomechanical follow-up results

\begin{tabular}{|c|c|c|}
\hline \multirow{2}{*}{ Variable } & \multicolumn{2}{|r|}{ Group A } \\
\hline & Preoperative & Postoperative \\
\hline \multicolumn{3}{|c|}{ Sagittal alignment $\left({ }^{\circ}\right)$} \\
\hline C2-7 & $-13.4 \pm 11.6$ & $-13.3 \pm 8.8$ \\
\hline FSU & $-0.2 \pm 3.8$ & $-0.2 \pm 4.0$ \\
\hline \multicolumn{3}{|l|}{$\mathrm{ROM}\left({ }^{\circ}\right)$} \\
\hline$C 2-7$ & $44.5 \pm 6.3$ & $44.3 \pm 5.7$ \\
\hline FSU & $10.0 \pm 1.6$ & $8.4 \pm 2.1$ \\
\hline \multicolumn{3}{|l|}{ Adjacent segment } \\
\hline Upper & $8.6 \pm 2.3$ & $8.4 \pm 2.0$ \\
\hline Lower & $8.4 \pm 2.2$ & $8.3 \pm 1.9$ \\
\hline FSU height (mm) & $37.0 \pm 2.1$ & $37.1 \pm 1.8$ \\
\hline \multicolumn{3}{|c|}{$\begin{array}{l}\text { Values are presented as mean } \pm \text { standard deviation. Group } A \text { : total } d i \\
\text { segmental unit, ROM : range of motion }\end{array}$} \\
\hline \multicolumn{3}{|c|}{ Table 6. Incidence of heterotopic ossification in Group A } \\
\hline McAfee class & \multicolumn{2}{|c|}{ No. of patient (\%) } \\
\hline 0 & \multicolumn{2}{|c|}{$5(29.4)$} \\
\hline I & \multicolumn{2}{|c|}{$4(23.5)$} \\
\hline$\|$ & \multicolumn{2}{|c|}{$3(17.6)$} \\
\hline III & \multicolumn{2}{|c|}{$2(11.8)$} \\
\hline IV & \multicolumn{2}{|c|}{$3(17.6)$} \\
\hline
\end{tabular}

Group A: Total disc replacement

ervation" was given by $88.2 \%$ of group A patients. However, the group B answers varied: "motion preservation" in 38.9\%, "no device use" in 27.8\%, and "cost effectiveness" in 22.2\%.

\section{DISCUSSION}

The primary goal of all operative treatment methods in patients with pure radiculopathy is decreased pain and sensorimotor deficits, as well as restore of working ability and quality of life. These goals can be reached by permanent decompression of the compressed nerve root. Various morphological causes (hard or soft disc or both) can lead to radiculopathy, which is treated using different techniques. These techniques differ in approach, complexity, aim, duration, and complications. We compared perioperative data and long-term outcomes of patients with pure radiculopathy treated at a single institution. These patients underwent de-
Table 7. Relationship between clinical outcomes and the presence of heterotopic ossification in group A and sagittal alignment C2-7, ROM, and FSU height in group B

\begin{tabular}{llcc}
\hline \multirow{2}{*}{ Variable } & \multicolumn{3}{c}{$p$-value } \\
\cline { 2 - 4 } & NDI & VAS of neck VAS of arm \\
\hline $\begin{array}{l}\text { Group A } \\
\quad \text { Heterotopic ossification } \\
\text { (Spearman correlation coefficient) }\end{array}$ & 0.143 & 0.451 & 0.091 \\
$\begin{array}{l}\text { Group B } \\
\text { Sagittal alignment C2-7 }\end{array}$ & 0.471 & 0.451 & 0.385 \\
ROM of FSU & 0.560 & 0.519 & 0.491 \\
FSU height & 0.075 & 0.195 & 0.068 \\
\hline
\end{tabular}

Group A : total disc replacement. Group B: posterior cervical foraminotomy. NDI : neck disability index, VAS : visual analog scale, FSU : functional segmental unit, ROM : range of motion

compression, with either anterior microdiscectomy and insertion of an artificial disc or posterior foraminotomy. Although both techniques helped preserve motion, they have different characteristics.

The advantages of TDR are preservation of motion and disc height, familiarity of the approach, and a relatively good long-term result including a lower incidence of adjacent segmental disease. Peng et al. ${ }^{25)}$ reported that TDR produces significant improvement in clinical outcomes after 2 years. Moreover, TDR restores segmental lordosis and preserves segmental motion up to 2 years postoperatively. In the present study, TDR showed good clinical outcomes, but 
whether motion preservation was questionable in some cases at a minimum 5-year follow-up. Moreover, TDR has disadvantages, such as HO, implant-related complications, and risk of anterior structural injury ${ }^{2,17,22,23,26,31)}$. Quan et al. reported that the Bryan TDR maintains favorable clinical and radiological results, preserves movement, and leads to satisfactory clinical outcomes in the majority of cases at the 8 -year follow-up ${ }^{26)}$. However, HO was evident in $48 \%$ of operated segments, and the incidence of $\mathrm{HO}$ causing restricted ROM of the prosthesis appeared to increase with time. In the same report, mean VAS score for both neck and arm pain was slightly higher in patients in whom HO developed than in those without HO. In the present study, no statistically significant correlation was detected between $\mathrm{HO}$ and clinical outcomes, although $\mathrm{HO}$ was evident in 12 of 17 (70.6\%) cases. However, the correlation was almost marginal $(p=0.091)$, suggesting possible significance in a long-term follow-up. Many studies have examined risk factors for $\mathrm{HO}$ after cervical TDR, such as male sex, old age, longer postoperative period, prosthesis type, and preoperative calcification of longitudinal ligaments and osteophyte ${ }^{5,15,20,34)}$. The reason for the high incidence of $\mathrm{HO}$ in our study was thought to be the difference in sex ratio (male : female $=12$ : 5) and prosthesis type.

Implant-related complications can be a problem with TDR. Quan et al. reported a case of posterior migration of the implant, whereas Hrabálek reported no implant-related complications, such as migration, loosening, or subsidence $^{26)}$. These results are consistent with previous studies, in which incidence of implant-related complications was very low $^{13,26,33)}$. In contrast with PCF, TDR has a risk of intraoperative or early complications related to the anterior approach including hoarseness, dysphagia, and cerebrospinal fluid leakage. Early complication rates for TDR are 5-30\%, and dysphagia is the most common complication ${ }^{2,17,23,31)}$. In the present study, two patients (11.7\%) had dysphagia after TDR, but no permanent symptoms were observed. Dysphagia after the anterior approach improves gradually over time, and severe complications are rare. However, it is clear that the anterior approach results in a higher complication rate than that of the posterior approach.

PCF also has advantages and disadvantages. The first advantage is that it does not require specialized instrumentation, so no instrument-related complications, such as infection or instrumental failure, occur after PCF. Additionally, PCF is more cost-effective compared with TDR. The cost of PCF in Korean insurance system is about one-half to onethird that of TDR. Four patients (22.2\%) in the group B chose cost-effectiveness as an important benefit of PCF, which may be related with patient's satisfaction. Another advantage of PCF is the low complication risk. Because PCF uses a posterior approach, the injury risk to anterior structures, such as the esophagus, carotid artery, and recurrent laryngeal nerve, is eliminated. In contrast, the most common complaint during the early postoperative period is neck pain and discomfort ${ }^{16,21}$. The extensive incision and dissection during PCF can increase neck discomfort and pain. Because of the slow recovery from this extensive incision, we used a tubular retractor system for minimally invasive surgery. We previously compared the open procedure and the tubular retractor assisted procedure for patients undergoing cervical radiculopathy ${ }^{18)}$. The neck pain VAS score after the tubular retractor-assisted procedure was significantly lower than that of the open procedure. The tubular retractor-assisted procedure also decreases the size of skin incision, length of nonsteroidal anti-inflammatory drug use, and length of hospital stay. Postoperative kyphosis can also be a problem with PCF. Risk factors associated with postoperative kyphotic deformity are old age, preoperative kyphosis, and extent of laminectomy ${ }^{11,14,16)}$. Jagannathan et al. reported that patients with postoperative kyphosis had lower quality of life outcomes ${ }^{14)}$. In contrast, postoperative kyphosis was not correlated with postoperative clinical outcomes in the present study, which may have been due to including patients who were relatively young and had single-level soft disc disease. Interestingly, decreased FSU height was marginally correlated with the NDI $(p=0.075)$ and arm VAS scores $(p=0.068$; Table 7$)$, possibly because of progression of foraminal stenosis may be related with decreased ROM and FSU height. This finding was caused by accelerated degeneration related to injury toe the 
facet, lamina, and soft tissue during surgery ${ }^{14)}$. In addition, C5 nerve root palsy can be a complication of $\mathrm{PCF}^{10,14,16,19)}$. Fortunately, C5 root palsy did not occur in the present study, possibly because only soft disc disease was treated. Yang reported that risk factors for C5 palsy include ossification of the posterior longitudinal ligament and foraminal stenosis ${ }^{32)}$. Soft disc herniation has a lower risk of C5 root palsy than hard disc or foraminal stenosis.

This study had some limitations. First, the data were obtained from a small number of patients and may be biased. Moreover, selection of surgical method was not randomized, although preoperative characteristics were not different between the two groups (Table 1). We explained the advantages and disadvantages of the two procedures to the patients, and the patients selected the surgical procedure. This factor may have influenced the patients' preconception for the surgery. Second, differences in the anterior and posterior approaches could have affected postoperative complications, such as dysphagia, neck pain, and hoarseness. However, the main objective of this study was the biomechanical follow-up results for motion preservation techniques. Also, PCF and TDR are the most popular motion-preservation techniques, and no comparative study has been conducted between the two techniques.

\section{CONCLUSION}

TDR and PCF provided favorable clinical and radiological outcomes for patients with unilateral cervical radiculopathy caused by posterolateral soft disc herniation, However, TDR has disadvantages including $\mathrm{HO}$ and anterior approach-related complications, and PCF has problems, including disc recurrence, progression of spondylosis, and neck pain. Therefore, we recommend TDR for patients with risks for progressing kyphosis (neck muscle atrophy, preoperative kyphosis, etc), posterior neck pain and re-herniation of a disc. In contrast, we suggest PCF for patients with risks for the anterior approach (structural problems, previous neck surgery, etc) and concerns about cost.

\section{References}

1. Aldrich F : Posterolateral microdisectomy for cervical monoradiculopathy caused by posterolateral soft cervical disc sequestration. J Neurosurg 72 : 370-377, 1990

2. Bazaz R, Lee MJ, Yoo JU : Incidence of dysphagia after anterior cervical spine surgery: a prospective study. Spine (Phila Pa 1976) 27 : 24532458, 2002

3. Beaurain J, Bernard P, Dufour T, Fuentes JM, Hovorka I, Huppert J, et al. : Intermediate clinical and radiological results of cervical TDR (Mobi-C) with up to 2 years of follow-up. Eur Spine J 18 : 841-850, 2009

4. Cağlar YS, Bozkurt M, Kahilogullari G, Tuna H, Bakir A, Torun F, et al. : Keyhole approach for posterior cervical discectomy: experience on 84 patients. Minim Invasive Neurosurg 50 : 7-11, 2007

5. Cho HJ, Shin MH, Huh JW, Ryu KS, Park CK : Heterotopic ossification following cervical total disc replacement: iatrogenic or constitutional? Korean J Spine 9 : 209-214, 2012

6. Cloward RB : The anterior approach for removal of ruptured cervical disks. J Neurosurg 15 : 602-617, 1958

7. Ducker TB, Zeidman SM : The posterior operative approach for cervical radiculopathy. Neurosurg Clin N Am 4 : 61-74, 1993

8. Duggal N, Pickett GE, Mitsis DK, Keller JL : Early clinical and biomechanical results following cervical arthroplasty. Neurosurg Focus 17 : E9, 2004

9. Fehlings MG, Gray RJ : Posterior cervical foraminotomy for the treatment of cervical radiculopathy. J Neurosurg Spine 10 : 343-344, 2009

10. Gala VC, O'Toole JE, Voyadzis JM, Fessler RG : Posterior minimally invasive approaches for the cervical spine. Orthop Clin North Am 38 : 339-349, 2007

11. Henderson CM, Hennessy RG, Henry M Jr, Shackelford GE : Posteriorlateral foraminotomy as an exclusive operative technique for cervical radiculopathy: a review of 846 consecutively operated cases. Neurosurgery $13: 504-512,1983$

12. Hilton DL Jr: Minimally invasive tubular access for posterior cervical foraminotomy with three-dimensional microscopic visualization and localization with anterior/posterior imaging. Spine J 7 : 154-158, 2007

13. Hrabálek L, Vaverka M, Houdek M : Cervical disc arthroplasty (Prodisc-C): analysis of 3 to 4- year follow up results. Rozhl Chir 88:634-641, 2009

14. Jagannathan J, Sherman JH, Szabo T, Shaffrey $\mathrm{Cl}$, Jane JA : The posterior cervical foraminotomy in the treatment of cervical disc/osteophyte disease: a single-surgeon experience with a minimum of 5 years' clinical and radiographic follow-up. J Neurosurg Spine $10: 347-356,2009$

15. Jin YJ, Park SB, Kim MJ, Kim KJ, Kim HJ : An analysis of heterotopic ossification in cervical disc arthroplasty: a novel morphologic classification of an ossified mass. Spine J 13 : 408-420, 2013

16. Jödicke $A$, Daentzer $D$, Kästner $S$, Asamoto $S$, Böker DK : Risk factors for outcome and complications of dorsal foraminotomy in cervical disc herniation. Surg Neurol 60 : 124-129; discussion 129-130, 2003 
17. Kang SH, Kim DK, Seo KM, Kim KT, Kim YB : Multi-level spinal fusion and postoperative prevertebral thickness increase the risk of dysphagia after anterior cervical spine surgery. J Clin Neurosci 18 : 1369-1373, 2011

18. Kim KT, Kim YB : Comparison between open procedure and tubular retractor assisted procedure for cervical radiculopathy: results of a randomized controlled study. J Korean Med Sci 24 : 649-653, 2009

19. Korinth MC, Krüger A, Oertel MF, Gilsbach JM : Posterior foraminotomy or anterior discectomy with polymethyl methacrylate interbody stabilization for cervical soft disc disease: results in 292 patients with monoradiculopathy. Spine (Phila Pa 1976) 31 : 1207-1214, 2006

20. Leung C, Casey AT, Goffin J, Kehr P, Liebig K, Lind B, et al. : Clinical significance of heterotopic ossification in cervical disc replacement: a prospective multicenter clinical trial. Neurosurgery 57 : 759-763, 2005

21. Lidar Z, Salame K : Minimally invasive posterior cervical discectomy for cervical radiculopathy: technique and clinical results. J Spinal Disord Tech 24 : 521-524, 2011

22. McAfee PC, Cunningham BW, Devine J, Williams E, Yu-Yahiro J : Classification of heterotopic ossification ( $\mathrm{HO}$ ) in artificial disk replacement. J Spinal Disord Tech 16 : 384-389, 2003

23. Morpeth JF, Williams MF : Vocal fold paresis after anterior cervical discectomy and fusion. Laryngoscope $110: 43-46,2000$

24. Park CK, Ryu KS, Lee KY, Lee HJ : Clinical outcome of lumbar total disc replacement using ProDisc- $L$ in degenerative disc disease: minimum 5-year follow-up results at a single institute. Spine (Phila Pa 1976) 37 : 672677, 2012

25. Peng CW, Yue WM, Basit A, Guo CM, Tow BP, Chen JL, et al. : Intermediate results of the prestige LP cervical disc replacement: clinical and radiological analysis with minimum two-year follow-up. Spine (Phila
Pa 1976) 36 : E105-111, 2011

26. Quan GM, Vital JM, Hansen S, Pointillart V : Eight-year clinical and radiological follow-up of the Bryan cervical disc arthroplasty. Spine (Phila Pa 1976) 36 : 639-646, 2011

27. Rodrigues MA, Hanel RA, Prevedello DM, Antoniuk A, Araújo JC : Posterior approach for soft cervical disc herniation: a neglected technique? Surg Neurol 55 : 17-22; discussion 22, 2001

28. Roh SW, Kim DH, Cardoso AC, Fessler RG : Endoscopic foraminotomy using MED system in cadaveric specimens. Spine (Phila Pa 1976) 25 : 260-264, 2000

29. Russell SM, Benjamin V : Posterior surgical approach to the cervical neural foramen for intervertebral disc disease. Neurosurgery 54 : 662665,2004

30. Ryu KS, Park CK, Jun SC, Huh HY : Radiological changes of the operated and adjacent segments following cervical arthroplasty after a minimum 24-month follow-up: comparison between the Bryan and Prodisc- $\mathrm{C}$ devices. J Neurosurg Spine 13 : 299-307, 2010

31. Stewart M, Johnston RA, Stewart I, Wilson JA : Swallowing performance following anterior cervical spine surgery. Br J Neurosurg 9 : 605-609, 1995

32. Yang CW, Fuh JL : C5 palsy after cervical spine decompression surgery. J Chin Med Assoc 76 : 363-364, 2013

33. Yi S, Lim JH, Choi KS, Sheen YC, Park HK, Jang IT : Comparison of anterior cervical foraminotomy vs arthroplasty for unilateral cervical radiculopathy. Surg Neurol 71 : 677-680; discussion 680, 2009

34. Yi S, Shin DA, Kim KN, Choi G, Shin HC, Kim KS, et al. : The predisposing factors for the heterotopic ossification after cervical artificial disc replacement. Spine J 13 : 1048-1054, 2013 